\title{
Validation of the Iranian Version of the ECOS-16 Questionnaire in Patients with Osteoporotic Vertebral Fractures
}

\author{
Parisa Azimi ${ }^{1}$, Taravat Yazdanian ${ }^{2}$, Ali Montazeri ${ }^{3}$ \\ ${ }^{1}$ Functional Neurosurgery Research Center, Shahid Beheshti University of Medical Sciences, Tehran, Iran \\ ${ }^{2}$ School of Medicine, Capital Medical University, Beijing, China \\ ${ }^{3}$ Mental Health Research Group, Health Metrics Research Centre, Iranian Institute for Health Sciences Research, \\ Academic Center for Education, Culture and Research, Tehran, Iran
}

\section{Study Design: Prospective clinical study.}

Purpose: To translate and validate the Quality of Life Questionnaire of the European Foundation for Osteoporosis (ECOS-16) in patients with osteoporotic vertebral fractures in Iran.

Overview of Literature: It is important to assess the psychometric properties of instruments measuring patient-reported outcomes. Methods: The translation was performed using the backward-forward translation method. The final version was generated by consensus among the translators. Every woman who had a T-score of $<-2.5$ completed ECOS-16. Patients were divided into two study groups according to the World Health Organization's criteria: those with at least one vertebral fracture (surgery group) and those with no fractures (control group). They were asked to respond to the questionnaire at three points in time: preoperative and twice within 1-week interval after surgery assessments (6-month follow-up). The 36-item short-form health survey (SF-36) also was completed. The psychometric properties of the questionnaire were assessed using internal consistency, test-retest reliability, convergent validity, discriminant validity, and responsiveness.

Results: Of 137 recruited women, 39 underwent surgery and 98 did not. Analysis of the ECOS-16 scales showed an appropriate reliability with Cronbach's alpha of $>0.70$ for all scales. Test-retest reliability as indicated by intraclass correlation coefficient was found to be $0.85(0.68-0.91)$. Additionally, the correlation of each item with its hypothesized domain of the ECOS-16 showed acceptable results, suggesting that the items had a substantial relationship with their own domains. Further analysis also indicated that the questionnaire was responsive to change (effect size, 0.85 ; standardized response mean, 0.93$)(p<0.001)$. Significant correlations existed between scores of similar subscales of ECOS-16 and SF-36 $(p<0.001)$.

Conclusions: ECOS-16 is an acceptable, reliable, valid, and responsive measure to assess the quality of life in patients with osteoporotic vertebral fractures.

Keywords: Iran; ECOS-16; Validity; Osteoporosis

Received Dec 14, 2016; Revised Jan 5, 2017; Accepted Jan 24, 2017

Corresponding author: Parisa Azimi

Functional Neurosurgery Research Center, Shohada Tajrish Hospital, Shahid Beheshti University of Medical Sciences,

Sharadari St., Tajrish Square, Tehran 1989934148, Iran

Tel: +98-2122749204, Fax: +98-2188265188,E-mail: parisa.azimi@gmail.com 


\section{Introduction}

Osteoporosis is a common bone disease, and the incidence of fragility fractures in postmenopausal osteoporotic women is high [1]. The incidence of non-traumatic osteoporotic fractures is rising globally at an alarming rate, representing a significant personal, social, and economic challenge [2]. Non-traumatic vertebral fractures due to osteoporosis may lead to reduced functionality and quality of life [3]. Thus, during the treatment of patients with osteoporosis, evaluation of functionality and pain is an important step in the decision-making process.

Numerous questionnaires with good validity and reliability exist for assessing the quality of life in patients with osteoporosis such as the European Foundation for Osteoporosis (QUALEFFO-41) [4,5], the Osteoporosis Quality of Life Questionnaire (OQLQ) [6], mini-OQLQ [7], the Osteoporosis Assessment Questionnaire, and the Osteoporosis Functional Disability Questionnaire. However, the length and administration time of these tools have limited their use in the routine clinical practice [8]. Thus, the Quality of Life Questionnaire of the European Foundation for Osteoporosis (ECOS-16) was developed as a brief and convenient tool for measuring the quality of life in postmenopausal women with osteoporosis [7].

ECOS-16 has been validated in patients with osteoporosis in many countries [8,9-11] but not in Iran. Hence, the aim of this study was to translate and validate ECOS16 as a measure of the functionality and quality of life in patients with osteoporotic vertebral fractures in Iran.

\section{Materials and Methods}

\section{The questionnaire}

ECOS-16 was developed to evaluate the quality of life in postmenopausal patients with osteoporosis. It is a brief, straightforward, self-administered questionnaire containing 16 easy-to-score items, 4 of which are taken from OQLQ [6] and the remaining 12 taken from the Questionnaire of the QUALEFFO-41 [4]. The 16 items are further divided into four subscales: pain (5 items), physical functioning (5 items), illness-related fear ( 2 items), and psychosocial functioning (4 items). Each question related to these items has five response options, ranging from 1 to 5 , where 5 represents the worst quality of life score [7]. ECOS-16 provides both subscale domain scores and an overall score.

\section{Translation}

The cross-cultural adaptation was performed based on guidelines including the following: (1) contact with ECOS-16 developers, (2) initial translations (forward translation from English into Persian), (3) synthesis, (4) backward translations, (5) expert team review, (6) test of the pre-final version, and (7) final version. Forward translation from English to Persian was independently completed by two bilingual translators, who were native Persian speakers and well conversant in English. One of the translators is a Neurosurgeon and the other is a fulltime translator with no medical background and was not informed of our investigation. The two forward translators and other research team members discussed revision and modification of the questionnaire regarding language expressions and cultural differences. A provisional Persian version of ECOS-16 was then obtained. Then, two other professional translators translated this provisional version back into the English language. Finally, an expert committee comprising translators, researchers, and an outcome methodologist reviewed the translation and cultural adaptation processes. After a careful review and cultural adaptation, few changes were made, and the provisional Persian version of the questionnaire was created. To test the provisional version, patients were invited to complete the pre-final ECOS-16 for assessment, and their feedback was collected. The researchers met once more to make final adjustments in response to this feedback, and the final Iranian version of ECOS-16 was obtained.

\section{Patients and data collection}

Between January 2013 and April 2016, the final Iranian version of ECOS-16 was administered to a sample of consecutive patients with osteoporosis who presented to the neurosurgery clinics in two hospitals in Tehran, Iran. Diagnosis was based on World Health Organization criteria and was confirmed by a bone mineral density (BMD) test using dual energy X-Ray absorptiometry (DXA) of the lumbar spine and/or the hip. The DXA results were expressed as BMD (T-scores), and patients with T-scores $\leq-2.5$ were included [12]. Vertebral fractures were defined based on Genant's classification [13]. There were no restrictions on patient selection based on types of osteoporotic vertebral fracture, age, or other characteristics. A trained neurosurgery resident collected the data for 
this study over the course of one complete calendar year. Among the included patients with osteoporosis, those with at least one vertebral fracture underwent surgery and were included in surgery group, while those with no fractures did not undergo surgery and were considered as the control group. Patients who underwent standard surgical procedures [14] were assessed at two points in time: preoperative and postoperative (6-month followup). Surgery for patients included vertebroplasty and kyphoplasty. The indication for vertebroplasty or kyphoplasty was chronically painful vertebral compression fractures in patients failing 4-6 weeks of conservative therapy. Contraindications to these procedures included fractures with a disruption of the posterior vertebral wall, neurological deficit, or complete collapse of the vertebral body [15].

\section{Additional measure}

The Iranian version of the 36-item short-form health survey (SF-36) was also simultaneously completed. It includes 36 items in eight domains: physical functioning, social functioning, role limitations due to emotional problems, role limitations due to physical problems, vitality, mental health, bodily pain, and general health perception. The score for each subscale ranges from 0 to 100 , with lower scores indicating worse conditions [16]. In this study bodily pain, physical functioning, mental health, and vitality were used for evaluation.

\section{Statistical analysis}

1) Reliability

Reliability tests included evaluations for internal consistency and test-retest reliability. Cronbach's alpha was used to evaluate internal consistency with pre-established values indicating acceptable $(>0.7)$, good $(>0.8)$, and excellent (>0.9) internal consistency [17]. To ensure the stability of the measurement over time, the test-retest reliability of the final version of ECOS-16 at two postoperative assessments, "1-week test-retest analysis," was conducted using intraclass correlation coefficients (ICCs). An ICC value above 0.80 was considered as the evidence of excellent stability [17].

\section{2) Validity}

We used three types of validity. (1) Known-groups com- parison (discriminant validity): It was performed to test how well the questionnaire discriminates between subgroups of patients who differ according to the treatment received (surgery vs. no surgery). It was hypothesized that patients who received surgery would have a higher score (worse condition) on ECOS-16 at preoperative assessment. One-way analysis of variance was performed to test the study hypothesis. (2) Criterion validity (convergent validity): The correlation between changes on ECOS-16 and SF-36 was evaluated. Because SF-36 was validated in Iran, we used this questionnaire as the gold standard to assess the extent to which similar concepts on these questionnaires correlate to each other. (3) Item-scale correlations: Correlations were calculated using Pearson correlation coefficient $(r)$. It was expected that item scores would show a higher correlation with own hypothesized scale than other scales. Correlation values of 0.40 or above were considered satisfactory [17].

\section{3) Responsiveness to change}

A questionnaire's responsiveness refers to its capacity to detect the presence of a clinical change. Patients' preoperative and postoperative scores were compared using paired $t$ test in order to examine whether ECOS-16 was able to capture the change after surgery [18]. In addition, the ECOS-16 responsiveness was tested using effect size (ES) and standardized response mean (SRM). ES refers to the difference between average preoperative and postoperative scores, divided by the standard deviation of the preoperative score. SRM divides this difference by the standard deviation of change scores [18]. General rules for estimating the magnitude of ES or SRM are as follows: $<0.20$, trivial effect; $0.20-0.50$, small effect; $0.50-0.80$, moderate effect; and $>0.80$, large effect [18]. In the other words, a greater value of ES and SRM suggested a better responsiveness of ECOS-16.

\section{Ethics}

The Ethics Committee of the Shahid Beheshti University of Medical Sciences approved the study.

\section{Results}

\section{Patients' characteristics}

In total, 137 postmenopausal women with osteoporosis 
completed the questionnaire. The mean age of the patients was 58.6 (standard deviation, 7.1) years; most of them were married (67.9\%) and had completed a primary or secondary education (70.1\%). All the patients had an osteoporosis intensity score (T-score) $\leq-2.5$ and received bisphosphonate alendronate and calcitonin. They also received calcium and vitamin D3 as supplements. The characteristics of the patients are shown in Table 1.

Table 1. Characteristics of the study sample $(n=137)$

\begin{tabular}{|c|c|}
\hline Characteristic & No. $(\%)$ \\
\hline \multicolumn{2}{|l|}{ Age (yr) } \\
\hline Mean \pm standard deviation & $58.6 \pm 7.1$ \\
\hline Range & $55-82$ \\
\hline Age at menopause (yr) & $47.9 \pm 4.9$ \\
\hline Body mass index $\left(\mathrm{kg} / \mathrm{m}^{2}\right)$ & $28.4 \pm 5.3$ \\
\hline \multicolumn{2}{|l|}{ Educational status } \\
\hline Illiterate & $23(16.8)$ \\
\hline Primary & $69(50.4)$ \\
\hline Secondary & $27(19.7)$ \\
\hline College/university & $18(13.1)$ \\
\hline \multicolumn{2}{|l|}{ Marital status } \\
\hline Single & $26(18.9)$ \\
\hline Married & $93(67.9)$ \\
\hline Divorced/widowed & $18(13.2)$ \\
\hline \multicolumn{2}{|l|}{ Received surgery } \\
\hline No & $98(71.5)$ \\
\hline Yes & $39(28.5)$ \\
\hline \multicolumn{2}{|c|}{$\begin{array}{l}\text { Distribution of patients based on } \\
\text { the fracture site }(n=39)\end{array}$} \\
\hline \multicolumn{2}{|c|}{ Level $^{\mathrm{a})}$} \\
\hline L1 & $20(29.4)$ \\
\hline $\mathrm{L} 2$ & $9(13.2)$ \\
\hline L3 & $2(2.9)$ \\
\hline Ł4 & $6(8.8)$ \\
\hline L5 & $1(1.5)$ \\
\hline $\mathrm{T} 7$ & $6(8.8)$ \\
\hline T8 & $5(7.3)$ \\
\hline T9 & $4(6.0)$ \\
\hline $\mathrm{T} 10$ & $1(1.5)$ \\
\hline $\mathrm{T} 11$ & $6(8.8)$ \\
\hline $\mathrm{T} 12$ & $8(11.8)$ \\
\hline
\end{tabular}

a)Level of fractures for 39 patients who received surgery. Since some patients had more that one fracture the total number of fractures levels exceeds 39 .

\section{Psychometric properties}

The internal consistency of ECOS-16 measured using the Cronbach's alpha coefficient ranged from 0.82 to 0.84 at the preoperative assessment, indicating a satisfactory result. These results are shown in Table 2. Further analysis also indicated that the test-retest ICC value (95\% confidence interval) was $0.85(0.68-0.91)$ for the total score of ECOS-16, indicating a good reliability.

The validity of ECOS-16 was evaluated using item-scale correlations, criterion validity, and known-groups comparison (discriminant validity). The item-scale correlation matrix between each item and the three ECOS-16 subscales including pain, physical functioning, and mental function (fear of illness+psychosocial functioning) are shown in Table 3. All correlations between the items and its hypothesized scale showed satisfactory results, suggesting that the items had a substantial association with their own subscales. Pearson correlation coefficient exceeded the pre-established level $(r \geq 0.40)$, ranging from 0.54 (Q4) to 0.71 (Q13). The criterion validity analysis showed significant correlations between all subscales in the ECOS16 questionnaire and their corresponding subscales in SF$36(p<0.001)$ (Table 4). It also exhibited good discriminate validity, with both subscale and overall scores differing between the categories of surgery and control groups (Table 5).

Responsiveness to change was evaluated using paired $t$-test. At all instances, ECOS-16 detected changes after intervention (surgery), indicating improvements in all subscales (Table 6). The ES and SRM totals were 0.85 and 0.93 , respectively.

Table 2. Descriptive statistics for the ECOS-16 at first assessment (n=137)

\begin{tabular}{|ccc|} 
Items & $\begin{array}{c}\text { No. of } \\
\text { items }\end{array}$ & $\begin{array}{r}\text { Cronbach alpha } \\
\text { coefficient }^{\text {a) }}\end{array}$ \\
\hline Pain & 5 & 0.82 \\
Physical functioning & 5 & 0.84 \\
Mental function & 2 & 0.83 \\
\hline Fear of illness & 4 & \\
\hline Psychosocial functioning & 16 & 0.83 \\
\hline Total score of ECOS-16 & & \\
\hline
\end{tabular}

ECOS-16, Quality of Life Questionnaire of the European Foundation for Osteoporosis.

${ }^{\text {a) }} \mathrm{A}$ value of 0.70 or above indicates adequate reliability. 
Table 3. Item-scale correlation matrix for the four ECOS-16 subscales $(n=137)^{\text {a) }}$

\begin{tabular}{|c|c|c|c|c|}
\hline Items (item number) & Pain & $\begin{array}{l}\text { Physical } \\
\text { functioning }\end{array}$ & $\begin{array}{l}\text { Fears of } \\
\text { illness }\end{array}$ & $\begin{array}{l}\text { Psychological } \\
\text { functioning }\end{array}$ \\
\hline How often have you had back pain in the last week? & 0.71 & 0.19 & 0.13 & 0.14 \\
\hline How severe is your back pain? & 0.67 & 0.20 & 0.18 & 0.25 \\
\hline $\begin{array}{l}\text { How much distress or discomfort have you had because it has been } \\
\text { painful to stand for a long time? }\end{array}$ & 0.59 & 0.23 & 0.21 & 0.18 \\
\hline $\begin{array}{l}\text { How much distress or discomfort have you had due to pain from } \\
\text { bending? }\end{array}$ & 0.54 & 0.28 & 0.14 & 0.19 \\
\hline Has the back pain disturbed your sleep in the last week? & 0.62 & 0.16 & 0.27 & 0.21 \\
\hline How difficult has it been for you to carry out the household activities? & 0.15 & 0.57 & 0.31 & 0.23 \\
\hline Can you climb stairs to the next floor of a house? & 0.26 & 0.68 & 0.22 & 0.28 \\
\hline Do you have problems with dressing? & 0.24 & 0.61 & 0.27 & 0.21 \\
\hline How difficult has it been for you to bend? & 0.27 & 0.69 & 0.25 & 0.22 \\
\hline How much has your walking been limited? & 0.18 & 0.58 & 0.15 & 0.16 \\
\hline How difficult has it been for you to visit friends or relatives? & 0.33 & 0.17 & 0.68 & 0.34 \\
\hline Do you feel downhearted? & 0.17 & 0.11 & 0.63 & 0.20 \\
\hline Are you hopeful about your future? & 0.16 & 0.24 & 0.23 & 0.72 \\
\hline Do you feel frustrated? & 0.15 & 0.33 & 0.28 & 0.67 \\
\hline Are you afraid of falling? & 0.31 & 0.16 & 0.16 & 0.56 \\
\hline Are you afraid of getting a fracture? & 0.25 & 0.28 & 0.21 & 0.68 \\
\hline
\end{tabular}

ECOS-16, Quality of Life Questionnaire of the European Foundation for Osteoporosis.

${ }^{a}$ Pearson correlation $(r)$ equal to or greater than 0.40 was considered satisfactory (correlation: $\geq 0.81-1.0$, excellent; $0.61-0.80$, very good; $0.41-0.60$, good; 0.21-0.40, fair; and 0.0-0.20, poor) [17].

Table 4. Correlation coefficients between similar subscales of the ECOS-16 and the SF-36 measures ( $n=137)$

\begin{tabular}{llrr} 
ECOS-16 subscale & SF-36 subscale & Correlation coefficient $^{\text {a) }}$ & $p$-value \\
Pain & Bodily pain & -0.82 & $<0.001$ \\
Physical function & Physical functioning & -0.81 & $<0.001$ \\
Mental function $^{\text {c) }}$ & Mental health and vitality & -0.78 & $<0.001$ \\
\hline
\end{tabular}

ECOS-16, Quality of Life Questionnaire of the European Foundation for Osteoporosis; SF-36, 36-item short-form health survey.

${ }^{a)}$ Negative values indicate the opposite direction for scoring of the ECOS-16 and the SF-36; 'berived from Spearman's test; ${ }^{\text {cl }}$ Fears of illness and psychosocial functioning.

\section{Discussion}

The present study results showed excellent reliability as well as good validity and responsiveness of the Persian version of ECOS-16. It can, therefore, be concluded that this version of ECOS-16 is a valuable tool for assessing patients with osteoporotic vertebral fractures and is comparable with versions in other languages [8,9-11]. However, some modifications performed in the current study due to linguistic issues of Persian patients should be kept in mind.
The Cronbach's alpha for the Persian version of ECOS16 exceeded the pre-established threshold, suggesting that this version had a satisfactory internal consistency. Our results are similar to those previously reported by other studies [7,8,9-11]. In addition, an ICC of 0.85 indicates that the Iranian version of ECOS-16 has good reliability, which is also in line with other studies $[8,9-11,19]$.

Significant correlations were found between subscales of ECOS-16 and SF-36. According to the meanings of the subscales, correlations between the pain domain of ECOS-16 and the bodily pain domain of SF-36 $(r=-0.82)$, 
Table 5. The ECOS-16 and the SF-36 scores for patients with and without vertebral fractures surgery

\begin{tabular}{|c|c|c|c|}
\hline Items & Received surgery (n=39) & Not receiving surgery $(\mathrm{n}=98)$ & $p$-value \\
\hline \multicolumn{4}{|l|}{ ECOS-16 subscales ${ }^{\text {a) }}$} \\
\hline Pain & $2.92 \pm 0.81$ & $2.39 \pm 0.92$ & $<0.001$ \\
\hline Physical functioning & $2.39 \pm 0.78$ & $1.97 \pm 0.81$ & 0.001 \\
\hline Fear of illness & $2.41 \pm 0.69$ & $1.98 \pm 0.75$ & 0.001 \\
\hline Psychosocial functioning & $2.57 \pm 0.83$ & $2.01 \pm 0.84$ & $<0.001$ \\
\hline Total score & $2.63 \pm 0.76$ & $2.11 \pm 0.80$ & $<0.001$ \\
\hline \multicolumn{4}{|l|}{ SF-36 subscales ${ }^{\text {b) }}$} \\
\hline Bodily pain & $35.8 \pm 20.6$ & $54.8 \pm 19.6$ & 0.02 \\
\hline Physical functioning & $42.6 \pm 20.2$ & $63.2 \pm 26.3$ & 0.03 \\
\hline Mental health+vitality & $43.6 \pm 18.2$ & $58.9 \pm 15.3$ & 0.04 \\
\hline
\end{tabular}

Values are presented as mean \pm standard deviation.

ECOS-16, Quality of Life Questionnaire of the European Foundation for Osteoporosis; SF-36, 36-item short-form health survey.

a)Lower scores on the ECOS-16 indicate better conditions; ${ }^{b /}$ Higher scores on the SF-36 indicate better conditions.

Table 6. Responsiveness to change as measured by the ECOS-16 ( $n=39)$

\begin{tabular}{lccc} 
Items & Preoperative & Postoperative & $p$-value \\
Pain & $2.92 \pm 0.81$ & $2.15 \pm 0.72$ & $<0.001$ \\
Physical functioning & $2.39 \pm 0.78$ & $1.76 \pm 0.67$ & $<0.001$ \\
\hline Fear of illness & $2.41 \pm 0.69$ & $1.92 \pm 0.65$ & $<0.001$ \\
\hline Psychosocial functioning & $2.57 \pm 0.83$ & $2.10 \pm 0.72$ & $<0.001$ \\
\hline Total score & $2.63 \pm 0.76$ & $1.99 \pm 0.71$ & $<0.001$ \\
\hline
\end{tabular}

Values are presented as mean \pm standard deviation.

ECOS-16, Quality of Life Questionnaire of the European Foundation for Osteoporosis.

${ }^{a}$ Derived from paired samples $t$-test.

the physical function domain of ECOS-16 and the physical functioning domain of SF-36 $(r=-0.81)$, and the mental function domain of ECOS-16 and the mental health and vitality domain of SF-36 $(r=-0.78)$ were observed. These results agree with good construct validity, reported in similar studies made using other languages $[8,11]$. A study on a Turkish version revealed a significant correlation between ECOS-16 and QUALEFFO-41 [9]. In the present study also, a known-groups comparison showed that the Iranian version of ECOS-16 discriminated well between patients who did and did not undergo surgery for vertebral fractures (Table 5), similar to the Moroccan version of the tool [10]. In addition, the responsiveness to a measure is an important determining factor for prospective clinical investigations. Our results showed a good responsiveness of ECOS-16, similar to another study [19].

To the authors' best knowledge, the Iranian version of ECOS-16 is the only condition-specific short outcome measure for patients with osteoporosis that has undergone psychometric evaluation in Iran. The results of the current study showed that the Iranian version of ECOS-16 has acceptable psychometric properties and is promising for use in research and clinical practice when evaluating women with postmenopausal osteoporosis, with or without vertebral fractures. The major limitations of our study are a small sample size of the surgery group and the absence of a gold standard. Hence, the results from this study should be interpreted with caution. Second, we were unable to compare the ECOS-16 scores among patients with different numbers of vertebral fractures. Third, the language we chose to adapt into is Persian, which does not account for all languages spoken in Iran, a multi-group nation where each minority group speaks a distinct language. This should be considered when using the tool. Finally, we performed only a limited number of psychometric tests. In the future, it might be beneficial to perform other tests 
in order to establish stronger psychometric indexes for ECOS-16.

\section{Conclusions}

The findings from this validation study showed that the Iranian version of ECOS-16 is a reliable, valid, and responsive measure in assessing the quality of life in patients with osteoporotic vertebral fractures.

\section{Conflict of Interest}

No potential conflict of interest relevant to this article was reported.

\section{Acknowledgments}

The authors thank the staff of the Neurosurgery Unit at Imam-Hossain Hospital, Tehran, Iran.

\section{References}

1. de Oliveira Ferreira N, da Silva RB, Arthuso M, Pinto-Neto AM, Caserta N, Costa-Paiva L. Prevalence of vertebral fractures and quality of life in a sample of postmenopausal Brazilian women with osteoporosis. Arch Osteoporos 2012;7:101-6.

2. Wade SW, Strader C, Fitzpatrick LA, Anthony MS. Sex- and age-specific incidence of non-traumatic fractures in selected industrialized countries. Arch Osteoporos 2012;7:219-27.

3. Astrand J, Nilsson J, Thorngren KG. Screening for osteoporosis reduced new fracture incidence by almost half: a 6-year follow-up of 592 fracture patients from an osteoporosis screening program. Acta Orthop 2012;83:661-5.

4. Lips P, Cooper C, Agnusdei D, et al. Quality of life in patients with vertebral fractures: validation of the Quality of Life Questionnaire of the European Foundation for Osteoporosis (QUALEFFO). Working Party for Quality of Life of the European Foundation for Osteoporosis. Osteoporos Int 1999;10:150-60.

5. Azimi P, Shahzadi S, Azhari S, Montazeri A. An outcome measure of functionality and quality of life in Iranian women with osteoporotic vertebral fractures: a validation study of the QUALEFFO-41. J Orthop Sci 2014;19:860-7.
6. Measuring quality of life in women with osteoporosis. Osteoporosis Quality of Life Study Group. Osteoporos Int 1997;7:478-87.

7. Badia X, Prieto L, Roset M, Diez-Perez A, Herdman M. Development of a short osteoporosis quality of life questionnaire by equating items from two existing instruments. J Clin Epidemiol 2002;55:32-40.

8. Salaffi F, Malavolta N, Cimmino MA, et al. Validity and reliability of the Italian version of the ECOS-16 questionnaire in postmenopausal women with prevalent vertebral fractures due to osteoporosis. Clin Exp Rheumatol 2007;25:390-403.

9. Yilmaz F, Dogu B, Sahin F, Sahin T, Kuran B. Reliability and validity of the Turkish version of the ECOS 16 questionnaire in postmenopausal osteoporosis. Eur J Phys Rehabil Med 2009;45:521-6.

10. Abourazzak FE, Allali F, Rostom S, et al. Factors influencing quality of life in Moroccan postmenopausal women with osteoporotic vertebral fracture assessed by ECOS 16 questionnaire. Health Qual Life Outcomes 2009;7:23.

11. Lee JS, Son SM, Goh TS, Kim TH, Noh EY. Validation of the ECOS-16 questionnaire in Koreans with osteoporosis. Asian Spine J 2016;10:877-85.

12. World Health Organization. WHO scientific group of the assessment of osteoporosis at primary health care level [Internet]. Geneva: World Health Organization; 2007 [cited 2017 May 1]. Available from: http://www. who.int/chp/topics/Osteoporosis.pdf.

13. Genant HK, Wu CY, van Kuijk C, Nevitt MC. Vertebral fracture assessment using a semiquantitative technique. J Bone Miner Res 1993;8:1137-48.

14. Epstein NE. Lumbar spine stenosis. In: Winn HR, editor. Youmans neurological surgery. 5th ed. Philadelphia: W.B. Saunders; 2011. p.2923-34.

15. Epstein NE. Bone metabolism and osteoporosis and its effects on spinal disease and surgical treatments. In: Winn HR, editor. Youmans neurological surgery. 5th ed. Philadelphia: W.B. Saunders; 2011. p.2767.

16. Montazeri A, Goshtasebi A, Vahdaninia M, Gandek B. The short form health survey (SF-36): translation and validation study of the Iranian version. Qual Life Res 2005;14:875-82.

17. Nunnally JC, Bernstien IH. Psychometric theory. 3rd ed. New York: McGraw-Hill; 1994.

18. Husted JA, Cook RJ, Farewell VT, Gladman DD. Methods for assessing responsiveness: a critical 
review and recommendations. J Clin Epidemiol 2000;53:459-68.

19. Badia X, Diez-Perez A, Lahoz R, Lizan L, Nogues X, Iborra J. The ECOS-16 questionnaire for the evalu- ation of health related quality of life in post-menopausal women with osteoporosis. Health Qual Life Outcomes 2004;2:41. 